$R M-75-74$

\title{
SOVIET POPULATION POLICY
}

\author{
George J. Demko
}

December 1975

Research Memoranda are interim reports on research being conducted by the International Institute for Applied Systems Analysis, and as such receive only limited scientific review. Views or opinions contained herein do not necessarily represent those of the Institute or of the National Member Organizations supporting the Institute. 



\section{Preface}

Interest in human settlement systems and policies has been a central part of urban-related work at IIASA since its inception. Recently this interest has given rise to a research effort focusing on the comparative study of the population and migration policies of the USA and the USSR. This paper, the second of a series dealing with that topic, is the text of an invited lecture given at IIASA by Professor Demko in September 1975. The views expressed about soviet population policy are those of the author and do not necessarily reflect those of IIASA.

December 1975

\section{Papers in the USA-USSR Population Study Series}

1. Galina Kiseleva, "The Influence of Urbanization on the Birthrate and Mortality Rate in Major Cities of the USSR," IIASA RM-75-68 (Laxenburg, Austria, International Institute for Applied Systems Analysis, 1975).

2. George J. Demko, "Soviet Population Policy," IIASA RM-75-74 (Laxenburg, Austria, International Institute for Applied Systems Analysis, 1975). 
1 


\section{Introduction}

The purpose of this paper is to investigate recent soviet responses to perceived population problems within the USSR. such responses can, in effect, be construed as official soviet population policy, whether identified as such by the soviet government or not. The demographic problems to which these responses or policy decisions are aimed are divided into two broad categories: 1) the national or aggregate problems, and 2) spatial or regional problems. These population problems have become acute, particularly the regional problems, and the debate and discussion in the scholarly journals, the press, and other media indicate that population policies are undergoing close scrutiny with a view to reformulation.

This paper, then, is divided into three parts, 1) a brief discussion of the definition of population policy and its interpretation in the soviet context, 2) a review of recent population trends and resultant problems in the soviet union, and finally, 3) an identification of the major policy instruments currently in force to ameliorate or solve these problems. The primary focus is, however, on this last section.

\section{Population Policy Defined}

\section{Population Policy Components}

Population policy has been variously defined by a great number of writers, very few of whom have agreed on its precise meaning and component parts. Two recent excellent statements by Driver ${ }^{1}$ and Berelson ${ }^{2}$ have identified many of the difficulties of defining and identifying policy as it relates to population issues and provide the basis for the following formulation.

In its most inclusive sense, population policy is a set of actions, stated or unstated, intended or unintended, by a government (national or local), organization or interest group which affects population size, growth rate, composition or distribution. The major components of any policy should include at least five stages: 1) awareness of a problem, 2) goal formation (including short and long term goals), 3) goal adoption, 4) selection, application and enforcement of instruments or means to achieve set goals, and 5) an instrument evaluation mechanism. Each of these arbitrarily defined components merits elaboration which would be impossible and inappropriate in this paper. It should be noted, however, that the instrument selection stage is the main focus of this study.

${ }^{1}$ E. D. Driver, Essays on Population Policy (Lexington, Massachusetts: Lexington Books, 1972).

2 B. Berelson, ed., Population Policy in Developed Countries (New York: McGraw-Hill, 1974). 
In addition to the main components of policy formation identified above, there are two other issues which must be identified. The first of these is the value system (prevailing philosophy in Driver's terms) ${ }^{3}$ against which the decisions in each stage are set and which heavily influence policy formation. For example, in a society where aborting fetuses is overwhelmingly unacceptable, abortion is unlikely to be adopted as a policy instrument to affect fertility levels. In a more spatial context, a family allowance program designed to increase fertility levels may be very effective in one region and totally ineffective in another as a result of strong spatial variations in values held by subgroups of the population.

The second issue of great importance in identifying a body of policy affecting population is that of other social and economic policies which, though not explicitly aimed at population problems, impinge upon and seriously affect demographic variables. This elusive and complex set of policies and related instruments is often ignored or only lightly considered in most discussions or descriptions of population policy. The policies are, however, of great importance and, with regard to some demographic processes such as urbanization and redistribution, may be of primary significance. National and regional health, education, unemployment compensation, and transportation policies and their impact on population growth, composition, and distribution are obvious examples. Given this definition of population policy and the related discussion, let us now turn our attention to their application in the soviet context.

\section{Population Policy Interpretation in the Soviet Union}

There have been a number of articles published by nonSoviets on population policy in the Soviet Union, most of which conclude that a coherent and consistent population policy does not exist. This may be accepted as true only if one adheres to a narrow definition of population policy as an intended, identified set of government actions directed at all population problems within a society. Such a population policy does not exist in the Soviet Union nor in any other country of the world at the present time. The inconsistency of policy instruments in the Soviet Union reflected, for example, in the ease of access to abortion, on the one hand, and family allowance policy, on the other, is really understandable when one realizes that the latter is a population policy instrument (as well as a welfare policy instrument) and the former a policy instrument directed at women's rights. Thus, although they may be contradictory in terms of their demographic effects, they are perfectly consistent in terms of the goals with which each is identified. In fact, the

3 Driver, pp. 9-12. 
Soviet government is consistent in that it does and has discouraged abortion as a means for reducing fertility. 4

The family allowance and abortion discussion raises another point concerning the Western literature on Soviet population policy, and that is the great emphasis placed on fertility-related policy instruments and the exclusion of non-demographically explicit policies affecting not only fertility but also urbanization and distribution. Such measures include regional wage differentials, regional allocation of investment funds for housing, and others (to be discussed later) which may be more readily identified as regional economic development, labor, or housing policy instruments but which can and do affect population processes and problems.

Given this policy background, it is clear that any evaluation or description of Soviet population policy must include more than a consideration of explicit growth or fertility policies and be cognizant of the importance and impact of impinging, non-explicitly demographic policies that exist in the system. Moreover, in the context of the Soviet Union, as well as the other socialist countries of Eastern Europe, the overwhelming importance of centralized economic planning must be considered in any discussion of population policy. In these systems population is viewed as a resource and the working population as a component of the "productive forces" along with tools, factories, and supporting economic infrastructure. ${ }^{5}$ Thus, one of the most important sources to be utilized in identifying the entire range of population policy measures is the economic plan, the five-year as well as longer range plans, since it is unlikely that a separate and independent body of population policy exists, even with regard to fertility, when population is crucial to and subsumed under the umbrella of economic policy.

\section{Recent Population Trends}

The major trends with which this paper is concerned are those related to fertility, and the natural increase and redistribution of the Soviet population at the national and

${ }^{4}$ See H. P. David, "Abortion and Family Planning in the Soviet Union: Public Policies and Private Behaviors," Paper presented at a Symposium in the Soviet Population Crisis, April 13, 1973. Columbus, Ohio, Ohio State University, pp. 10-11. See also reprint in Journal of Biosocial Science, 6,4 (1974), 417 ff.

50. Kudinov, "Strategy for the Distribution of Productive Forces in the Soviet Union" in $\mathrm{H}$. Swain (ed.) The IIASA Project on Urban and Regional Systems: A Status Report (Laxenburg, Austria: International Institute for Applied Systems Analysis, 1975) p. 10. 
regional levels. Since World war II there has been a steady decline in birthrates and the rate of natural increase and this decline has become particularly marked since the early 1960's. In 1960 , the crude birthrate was 24.9 per 1,000 population and rate of natural increase 17.8 per thousand, or about $1.8 \%$ per year. By 1970, the birthrate had dropped to 17.4 per thousand and the rate of natural increase to 9.2 per thousand, or less than $1 \%$ per year. 6 These trends have been amply documented in the literature of the Soviet Union and the West and have been attributed to two sets of factors. The first of these sets of factors relates to attitudinal changes on the part of the Soviet population toward family size and child rearing. Among the specific reasons cited for these attitudinal changes leading to lowered fertility are those associated with the rapid urbanization and industrialization processes. in the USSR, including the rising aspirations of parents with regard to levels of living and the related higher costs of raising children in an urban-industrial context, the extraordinarily high rate of female participation in the labor force, and the difficulty in acquiring housing as well as its general shortage. The second set of factors relates to the widespread availability of the means to prevent births, including abortion and means of contraception.

The trends described above have certainly not gone unnoticed by soviet officials and the problem of declining rates of population growth has been and is being discussed publicly and at many levels. Clearly these trends augur ill in terms of future labor and military needs.

\section{Spatial Variations in Soviet Fertility and Growth}

In addition to the problem presented above in terms of the aggregate figures, there is the exacerbating problem of regional or spatial variations in fertility and growth. The figures in Table 1 divide the USSR into three large regions, the European area, the Eastern portion of the RSFSR, and the Southern Caucasus and Central Asia; the figures further indicate interesting spatial gradations in fertility and growth. The European portion of the country is characterized by rates of natural increase well below 1\% per year, with some sections already characterized by levels of growth below that of replacement. The Eastern regions of the RSFSR are characterized by medium to low levels of natural increase, with a number of areas already below $1 \%$ growth per year. In contrast, the Southern Caucasus and Central Asian areas are marked by very high birth and natural increase rates, with birthrates well over twenty per thousand and natural increase levels exceeding $2.5 \%$.

Corroborative figures for the spatial variation in fertility can be found in Table 2 , which lists the results of soviet survey research regarding the intended number of children for families in selected regions of the country. 
Table 1. Birth and natural increase rates for selected regions of the USSR, 1970 .

\begin{tabular}{|c|c|c|}
\hline Region & Birthrate & $\begin{array}{l}\text { Rate of } \\
\text { Natural Increase }\end{array}$ \\
\hline $\begin{array}{l}\text { European USSR } \\
\text { Leningrad oblast } \\
\text { Pskov Oblast } \\
\text { Moscow Oblast } \\
\text { Kalinin Oblast } \\
\text { Ukraine SSR } \\
\text { Latvian SSR }\end{array}$ & $\begin{array}{l}12.6 / 1,000 \\
11.5 / 1,000 \\
11.9 / 1,000 \\
11.0 / 1,000 \\
15.2 / 1,000 \\
14.5 / 1,000\end{array}$ & $\begin{array}{rr}3.4 / 1,000 & (.34 \%) \\
-1.6 / 1,000 & (-.16 \%) \\
2.4 / 1,000 & (.24 \%) \\
0.9 / 1,000 & (.09 \%) \\
6.3 / 1,000 & (.63 \%) \\
3.3 / 1,000 & (.33 \%)\end{array}$ \\
\hline $\begin{array}{l}\text { Eastern RSFSR } \\
\text { West Siberia } \\
\text { Novosibirsk oblast } \\
\text { Irkutsk Oblast } \\
\text { Urals Region } \\
\text { Sverdlovsk Oblast }\end{array}$ & $\begin{array}{l}15.2 / 1,000 \\
14.2 / 1,000 \\
17.4 / 1,000 \\
15.3 / 1,000 \\
14.5 / 1,000\end{array}$ & $\begin{array}{l}7.1 / 1,000 \\
6.3 / 1,000 \\
9.9 / 1,000 \\
6.8 / 1,000 \\
6.1 / 1,000\end{array}$ \\
\hline $\begin{array}{l}\text { Southern Caucasus } \& \text { Central Asia } \\
\text { Azerbaydzhan SSR } \\
\text { Armenian SSR } \\
\text { Turkmen SSR } \\
\text { Uzbek SSR }\end{array}$ & $\begin{array}{l}29.2 / 1,000 \\
22.1 / 1,000 \\
35.2 / 1,000 \\
33.5 / 1,000\end{array}$ & $\begin{array}{ll}22.5 / 1,000 & (2.25 \%) \\
17.0 / 1,000 & (1.7 \%) \\
28.6 / 1,000 & (2.86 \%) \\
28.0 / 1,000 & (2.8 \%)\end{array}$ \\
\hline USSR & $17.4 / 1,000$ & $9.2 / 1 ; 000$ \\
\hline
\end{tabular}

Source: Vestnik Statistiki, 12 (1971), 76-79.

Table 2. Average intended number of children for selected regions of the USSR.

\begin{tabular}{lc}
\hline \multicolumn{1}{c}{ Region } & Intended \\
\hline Northwest & 1.99 \\
Central Industrial & 1.91 \\
Urals & 2.31 \\
West Siberia & 2.41 \\
Ukraine SSR & 2.07 \\
Estonian SSR & 2.29 \\
Kazakh SSR & 3.19 \\
Armenian SSR & 3.42 \\
Tadzhik SSR & 4.08 \\
Uzbek SSR & 4.31 \\
Azerbaydzhan SSR & 4.25 \\
\hline
\end{tabular}

Source: V. Belova, "Survey of Attitudes on the Ideal and Expected Number of Children," Vestnik Statistiki (June 1971), 30 . 
Regional Migration Balances

In order to complete the picture of regional population growth trends in the USSR the question of internal migration must be considered. Although precise migration data are not readily available, a number of migration estimates have been made for republics and regions by Soviet and Western scholars and this information provides a more complete view of the regional population problem. The data in Table 3 allow a number of generalizations to be made. With regard to the European portion of the country there have been significant gains in the Ukraine, the Northwest, Central Industrial Region, the Baltic Republics and the North Caucasus. Significant losses have been experienced in the Central Chernozem, Volga-Vyatka and Southwest regions, in addition to the Belorussian SSR. In general, these figures appear to represent movement to regions of higher levels of living and employment opportunity and away from ruralagrarian regions. The Eastern portions of RSFSR are characterized by significant out-migration from every region except the Far East which experienced a positive net migration balance. The Southern Caucasus and Central Asian regions, on the other hand, were noteworthy for heavy in-migration with the exception of the Azerbaydzhan SSR.

The general migration patterns described above obviously disguise a complex set of processes which are difficult to disentangle because of the paucity of specific origin and destination information. There are, of course, some speculations that can be made based on related and fragmentary data. The migration pattern in the European section of the country appears to be a movement related to the normal rural to urban migration process experienced by many developed countries. The rate of this movement into the major urban industrial centers of the European section, however, has been exceedingly rapid, so much so that Soviet officials have introduced legal limitations on migration into selected cities. 7 This measure has been necessary in order to prevent diseconomies of scale in the major industrial centers and to allow for a respite in the demand for services by rapidly growing urban centers. There is a growing body of evidence in the soviet literature expressing the need for diverting this movement of people to small and medium-sized cities and especially to the eastern regions of the RSFSR. ${ }^{8}$ It has also

${ }^{7}$ See M. F. Parkins, City Planning in Soviet Russia (Chicago: University of Chicago Press, 1953), pp. 50-52.

${ }^{8}$ For a discussion of soviet attempts to limit growth of large urban centers and related urban policies see, $R$. Wightman and $C$. ZumBrunnen, "Optimal City Size: Soviet Attempts to Limit Urban Growth," paper presented at the Midwest Slavic Conference, Cleveland, Ohio, Cleveland State University, May 2, 1975. 
Table 3. Net migration balances for Union Republics and major economic regions, 1959-1970.

Union Republics

RSFSR

Ukraine

Lithuania

Latvia

Estonia

Georgia

Azerbaydzhan

Armenia

Uzbekistan

Kirghizia

Tadzhikistan

Turkmenia

Kazakhstan

Belorussia

Moldavia
Thousands of Net Migrants

$-1,484$

541

50

156

92

$-77$

$-55$

145

410

166

149

12

875

$-266$

76

\section{Economic Regions}

Northwest

Central Industrial

Volga-Vyatka

$-831$

Central Chernozem

$-500$

Volga

46

North Caucasus

911

Urals

$-888$

West Siberia

$-732$

East Siberia

$-117$

Far East

140

Don-Dneiper

Southwest

402

South

Baltic

$-589$

753

365

Transcaucasia

Central Asia

Kazakhstan

875

Belorussia

$-266$

Moldavia

Source: Peter J. Grandstaff, "Economic Aspects of Interregional Migration in the USSR (1959-1970)," paper presented at the annual meeting of the American Association for the Advancement of Slavic Studies, March 15-18, 1972 (mimeo), p. 13 . 
been noted that the reserves of rural population available for migration to urban-industrial centers are approaching exhaustion and, coupled with the low and declining rates of natural increase mentioned earlier, will present a regional labor problem to planners in the region.

The migration process in the Eastern regions of the RSFSR appears to be obvious in that heavy out-migration is the rule. This process has a number of underlying dimensions which also require elaboration. The migration of soviets into the Eastern Regions from other areas of the country is problematic in that it is characterized by a high turnover rate. Most of the inmigration from outside areas is directed into urban-industrial centers, stay a few years or less and leave. There is also a heavy within-region migration from rural to urban areas of the region (see Table 4). The combination of heavy turnover of migrants from outside the region, the lack of skills of urban

Table 4. Total, urban and rural migration balances for Western and Eastern Siberia, 1959-1965 (IN THOUSANDS).

\begin{tabular}{lccc}
\hline Kray or Oblast & Total & Urban & Rural \\
\hline Altay Kray & -209 & +149 & -358 \\
Kemerovo Oblast & -49 & +87 & -136 \\
Novosibirsk Oblast & -68 & +133 & -201 \\
Omsk Oblast & -51 & +120 & -171 \\
Tomsk Oblast & -37 & +62 & -99 \\
Tyumen Oblast & +65 & - & - \\
\hline \multicolumn{1}{c}{ WESTERN SIBERIA } & -349 & +551 & -965 \\
Krasnoyarsk Kray & +10 & +259 & -249 \\
Irkutsk Oblast & +29 & +183 & -154 \\
Chita Oblast & -76 & - & -72 \\
Buryat ASSR & -1 & +24 & -25 \\
Tuva ASSR & +5 & +21 & -16 \\
\hline \multicolumn{1}{c}{ EASTERN SIBERIA } & -33 & +483 & -516 \\
$\quad$ & & & \\
TOTAL (EASTERN E WESTERN & -382 & +1034 & -1481 \\
$\quad$ SIBERIA) & & & \\
\hline
\end{tabular}

Source: Zh. A. Zayonchkovskaya and D. M. Zakharina, "Problems of Providing Siberia with Manpower," Problemy Razvitiya Vostochnykh Rayonov SSSR (Moscow: Nauka, 1971). 
arrivals from within the region, and the medium to low rates of natural population growth of the region present labor problems now, as well as increased labor problems in the future.

The migration picture in the central Asian area is one of great contrast with the Eastern regions of the RSFSR, in that it is characterized by high rates of in-migration. Given the recent ethnic data of the 1970 Census and other soviet data there is evidence that a large proportion of the in-migration to the region is made up of non-Central Asian ethnic groups. 9 The target of much of this migration has been the urban centers. For example, the Russian population of Tashkent has increased from $9.7 \%$ in 1897 , to $32.4 \%$ in 1926 , to $43.8 \%$ in 1959 in contrast to the indigenous population which decreased from $75.1 \%$ in 1897 , to $52.6 \%$ in 1926 , and amounted to $33.9 \%$ in 1959.10 The inmigration of Russians and other slavic groups has been clearly in response to the regional need for skilled workers and cadres in a rapidly industrializing region.

\section{Summary of the Regional Population Growth Problems}

The discussion to this point has focused primarily on regional demographic processes and disparities in the USSR. The patterns discussed above add to the soviet population problem when coupled with the Soviet plan for regional economic development and regional labor requirements.

The rural regions of the European section of the country have long been a reservoir of surplus labor for the growing urban-industrial nodes of the area. The rural to urban migration within the region has met the labor requirements of cities such as Moscow, Leningrad, and Kiev and, in fact, has been so great that restrictions have been imposed to slow this movement. Less successful has been the attempt to divert this rural surplus to the Eastern regions of the Siberias and the Urals and even the migration that has taken place has been characterized by a high return rate. Thus, the Eastern regions of the RSFSR, where labor needs are great, given the emphasis on developing the resources of the region, are experiencing net losses owing to migration and natural growth rates at medium to low levels. The Siberias and Urals are presently severe problem areas in terms of labor needs and there is little promise for relief given the migration and natural growth patterns.

${ }^{9}$ See V. V. Pokshishevkiy, "Urbanization and Ethnogeographic Processes," Soviet Geography: Review and Translation, XIII, 2 (February 1972), 113-120.

${ }^{10}$ Ibid., p. 117. 
Central Asia is an area of extraordinary natural population increase and high positive net migration balances, rendering it a region of labor surplus. As put by a Soviet author, "As a result of the more rapid rate of population growth in Central Asia, the gap between the region's per capita industrial output and that of the USSR has been steadily widening. 11

A major dimension of the population crisis in the USSR then stems from the disparities between regional labor needs and existing natural growth and migration patterns. Some Western scholars have recently emphasized the ethnic population problem or the Soviet concern for the rapid rate of growth of the Muslim nationalities compared to that of the slavic groups. ${ }^{12}$ Although such an ethnic issue may be important in the minds of some soviet officials, there is little or no evidence that it represents a serious concern for slavic dominance in the Soviet population.

\section{Soviet Population Policy Instruments}

The discussion of Soviet population policy instruments which follows should be viewed in the context of the definition put forward earlier which includes measures or instruments which may not be readily identifiable as population specific policies. Thus, the focus will be upon three categories of policy instruments, 1) measures directly bearing upon demographic variables, particularly fertility and growth, 2) labor and manpower measures particularly related to population distribution problems, and 3) economic planning measures which affect all of the demographic processes. It should be noted that this categorization is arbitrary and the categories are not mutually exclusive. For example, categories two and three above overlap inasmuch as labor and manpower needs are considered in the five year and other plans.

\section{Explicit Demographic Policy Instruments}

This set of policies on policy instruments are those most easily identified as a part of population policy and run the gamut from legal through economic to persuasive measures. Among the legal measures are the divorce and abortion laws, both of which have antinatalist orientations in terms of their impacts, and both of which are not intended to achieve population goals.

${ }^{11}$ A. I. Imshchenetskiy, "Some Aspects of the Development and Location of Industry in the Central Asian Economic Region," Soviet Geography: Review and Translation, 13, 10 (December 1972), 709 .

${ }^{12}$ See, for example, David M. Heer, "Recent Developments in Soviet Population Policy," Studies in Family Planning, 3,11 (November 1972), $257 \mathrm{ff}$. 
The best example of an economic measure in this set is the family allowance program which has undergone great change in that originally it provided relatively handsome sums but presently has little impact since no significant payments begin until the birth of the fourth child (see Table 5). In fact, the present structure of payments exacerbates the regional demographic patterns in that it encourages high fertility in already high growth areas (i.e., Central Asia) and has little or no impact in areas of low fertility.

Table 5. Family allowance payments in the USSR (rubles).

1st 2nd 3rd 4 th 5 th 6 th 7 th 8 th 9 th 10 th 11 th

\begin{tabular}{lc|c|c|c|r|r|r|r|r|r|r}
$\begin{array}{l}\text { Cash } \\
\text { Payment }\end{array}$ & 0 & 0 & 20 & 65 & 85 & 100 & 125 & 125 & 175 & 175 & 250 \\
$\begin{array}{l}\text { Monthly } \\
\text { Payment }\end{array}$ & 0 & 0 & 0 & 4 & 6 & 7 & 10 & 10 & 12.5 & 12.5 & 15.0 \\
\hline
\end{tabular}

Source: A. Kvasha, "Concerning Some Instruments of Demographic Policy," in The Study of the Reproduction of Population, Academy of sciences of the USSR (Moscow: Nauka, 1968), p. 71 .

* The monthly payments begin with the child's second year and extend through the fifth year.

Persuasive measures utilized in an attempt to affect population trends include campaigns to encourage people to marry younger (accompanied by arguments extolling the virtues of doing so) as well as campaigns to encourage the three child family and discourage the single child family. 13 In contrast to these measures is the availability of contraceptives (with the exception of the pill).

The sample of measures above illustrates the set of more explicit demographic policy instruments and, in general, can be regarded as more effective in an antinatalist sense rather than pronatalist.

13 See B. Z. Urlanis, "Marxism and Birth Control," studies in Family Planning, 49 (January 1970), 2 . 


\section{Labor and Manpower Measures}

As noted earlier some of the most serious demographic problems in the USSR are those of regional differentials in population growth rates and counterproductive migration streams. Two legal measures which have been employed in an attempt to ameliorate this problem include 1) the withholding of internal passports (especially in the rural areas) to prevent out-migration of young people in labor deficit areas, 14 and 2) creation of special residency requirements for the largest cities in an attempt to stem the rapid flow of migrants to already heavily taxed urban centers. Neither of these measures has proven effective in stemming rural to urban migration flows inasmuch as they are easily circumvented.

An example of an economic measure employed to bring about a needed labor redistribution is the regional wage differentials (created by the state Committee on Labor and wage Problems of the USSR Council of Ministers) which are aimed at attracting labor to areas like Siberia, the Far East and the North. The lack of effectiveness of this measure is clearly evident in the migration tables above.

Until recently only a very loose system of persuasive/administrative measures to attempt redirection of migration streams existed. This system included the Komsomol organization and other local organizations which attempted to facilitate labor flows in needed directions. Since 1966, however, a state committee for the utilization of labor resources (gosudarstvennye komitety trudovykh resursov) has been created in each of the fifteen republics; their responsibilities include the provision of job information and placement services and the recruitment and resettlement of wageworkers within their republics. The effectiveness of this measure remains to be evaluated but it is interesting to note that no equivalent coordinating All-Union Committee was created (currently, coordination is left to the Resources Department of the USSR State Planning Committee).

The Soviet Five-Year Plan

One of the most important set of measures which the Soviets are utilizing to achieve demographic goals is the centralized economic planning mechanism. Despite the obvious interrelationships between centralized economic planning and population-manpower problems in a socialist society, few non-Soviet scholars have directed their attention to this area in a search for an emerging Soviet population policy. In order to determine whether measures are being taken via economic planning mechanism, the

14 Apparently this measure is no longer practical on any large scale although precise information on passport holders is not available. 
current (ninth) five-year plan for the development of the soviet economy ${ }^{15}$ was examined and a number of tentative conclusions were drawn. In the plan at least three groups of measures can be identified which are aimed at solving or at least coping with current population problems.

The first set of measures that can be cited relate to the aggregate problem or the overall low level of population growth and the projected manpower shortage. That the planners recognize the problem is obvious from the repeated statements in the plan calling for need to increase labor productivity. The following statement serves as an example:

In recent years the manpower needs of the national economy have been rising faster than the natural increase in the able-bodied population, and these needs have been met to a considerable degree by bringing into social production persons employed in the household or on the private subsidiary plot, farm as well as kolkhoz members. In the 1961-1965 period $10 \mathrm{million}$ persons employed in households or on private subsidiary farm plots were brought into socialized production, and 3.2 million kolkhoz members were also employed by state enterprises and organizations; in the 1966-1970 period the scale of this recruitment dropped to 3.6 and 2.1 million persons, respectively.

These sources for meeting manpower needs are now practically exhausted. By 1970 employment of the country's able-bodied population had reached the high level of 91-92\%, and the calculations show no essential change in the course of the Ninth Five-Year Plan. Accordingly, the Ninth Five-Year plan calls for the national economy's need for additional manpower to be met almost entirely from young people reaching working age. This means that the national economy's manpower needs will be provided for only through the high growth rates of labor productivity that have been outlined. ${ }^{16}$ [My emphasis.]

The pianned increase in labor productivity is designed to save the labor of thirty-two million workers. Of the proposed increased input in industry, $87 \%$ is to be obtained by raising

${ }^{15}$ See N.K. Baybakov, State Five-Year Plan for the Development of the USSR National Economy for the Period 1971-1975, Parts I \& II (Springfield, Virginia: Joint Publications Research Service, September 1972).

${ }^{16}$ Ibid., Part I, p. 88. 
labor productivity and in construction, 95\%. 17 The overall rise in labor productivity is scheduled to be $39 \%$ by 1975 , which will reduce the manpower needs in the production sphere for the five-year period from thirty-seven million additional workers to only 4.7 million. The planners estimate that the total manpower addition to the labor force will be approximately ten million people $(4.7$ million projected to go into production jobs and 5.3 million into education, public health, the service sphere and other "non-productive" branches. 18

The means of raising labor productivity are discussed throughout the plan but mainly include 1) increased development of science and engineering and the rapid introduction of this technology into production enterprises, 2) increased organizational efficiency through computerization and other means, and 3) strengthened work discipline involving both incentives and penalties. 19 clearly, the overall problem of lagging rates of growth and its manpower implications are recognized and measures are being taken to ameliorate the effects on the economy.

The second set of measures outlined in the plan are addressed to the serious spatial manpower problems outlined earlier. In addition to the planned increase in labor productivity in the labor deficit regions, industrial location procedures are being revised to take into account manpower problems. In locating new industrial enterprises "manpower resources need to be rationally utilized... and the development of cities should be made more orderly."20 It is explicitly stated that "in most of the republics and oblasts of the European part of the country, in the Urals, in Siberia and the Far East the strain on the manpower balance places a restriction on the possibility of developing labor-intensive branches of industry." 21 on the other hand, the Central Chernozem region, Moldavia, Western Belorussia, the Transcaucasus and Central Asian republics are singled out for the location of labor-intensive industries. 22

${ }^{17}$ Ibid., Part I, p. 41 .

${ }^{18}$ Ibid., Part I, pp. 25-26.

${ }^{19}$ Ibid., Part I, p. 41, Pravda, Jan. 6, 1973, p. 1, and Partinaya Zhizn, 4, Feb. 1972, pp. 6-7.

20 Baybakov, Part II, p. 253.

21 Ibid., Part II, p. 256.

22 Ibid., Part II, pp. 256-259. 
Industrial location decisions are also being made with respect to the sex ratios of regions. For example, new enterprises employing predominantly males are planned for cities such as Ivanovo where female labor is now dominant and industries employing female labor are planned for male dominated labor areas in the heavy industry areas in the ukraine and the Moscow area. 23 The plan also calls for plants in the large urban centers of the European section of the country to set up affiliates in the small and medium-sized cities in order to avail themselves of manpower in these locations which are relatively underdeveloped industrially. Simultaneously "a limit is being placed on further concentration of industry and population in the very large centers." 24

Particular attention is directed to the eastern regions of the RSFSR in the plan. In order to increase the flow of migration to the eastern regions and to reduce labor turnover increased investment in housing construction, municipal utilities and services and social and cultural institutions are planned at "very high rates." The housing issue has been emphasized in the plan and approximately two-thirds of the state capital investment in housing will be directed to the eastern and northern regions. 25 In addition, regional wage coefficients are being applied to hitherto uncovered occupations and being raised on formerly covered occupations in the eastern and northern regions. 26

There is little doubt that Soviet officials are acutely aware of the regional population and manpower problems and are implementing many varied measures to deal with it, both in the long and short run.

The third set of measures evident in the economic plan relate more directly to the problem of fertility and natural increase. Of particular interest are the improved benefits for working women. The number of days of paid leave to care for sick children is scheduled for increase and leave for pregnancy and childbirth is now available at $100 \%$ of pay regardless of length of service. Preschool construction to accommodate more than two million children is scheduled for the five-year period from state funds, expanded facilities for schools with extended day-care programs are planned, and increased scholarship payments for secondary and college age students were implemented

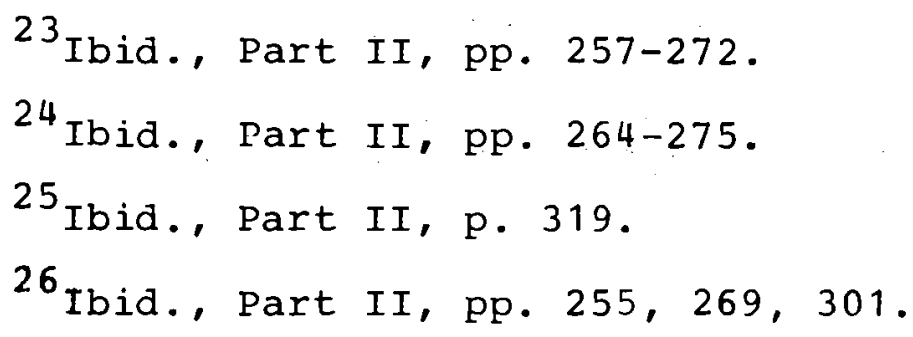


in september 1972. 27 These measures and others would certainly seem to be aimed at stemming the decline in the birthrate and raising the population's perception of ideal family size.

A final statement should be made about the orientation of the plan in general which may also have demographic implications. The ninth five-year plan places great emphasis on raising the material level of living of the Soviet population as indicated by the large share of the national income earmarked for the consumption fund and the emphasis on raising real income. 28 The latter measure seems to correlate positively with the opinions of such Soviet demographers as Urlanis and others who have found a positive relationship between rising income and increased ferEility. 29 In general, many of the measures implemented or projected in the plan are aimed at ameliorating or removing those factors most often associated with the soviet fertility decline (e.g., housing shortages, shortage of child-care facilities, wages, etc).

\section{Conclusion}

In conclusion, it is clear that soviet population policy is not easily identified since many policies and policy instruments are not explicitly identified with population goals. In fact, the most significant demographic impact policy instruments are those associated with economic planning and growth which is to say that population policy is subsumed under aggregate and regional economic growth policy.

Clearly, an understanding of population policy in a centrally planned, socialist society such as the Soviet Union is of great interest and utility. The centralized system enables the Soviet government to experiment with measures that would be difficult, if not impossible, to employ in other systems and thus we are afforded an opportunity to evaluate their effectiveness. In addition, the Soviet economy is a developed one and there is the possibility of assessing the appropriateness of their measures for potential use in other societies.

The obvious importance of population problems in the world today, further complicated by very great variations in types of problems from country to country and region to region, highlights

27 Ibid., Part II, pp. 305-306, and Part I, pp. 36-37.

${ }^{28}$ Per capita real income is scheduled to increase by approximately $.31 \%$ in the five-year period. Baybakou, Part II, pp. 296-298.

${ }^{29}$ See D. M. Heer, p. 262 . 
the significance of policy formation and implementation. Given the lack of experience in the realm of population policy and, more specifically, the ignorance regarding the effectiveness of specific policy instruments, it is essential to be aware of experiments in this area and to carefully evaluate their effectiveness and suitability for solving population problems. The Soviet Union as well as the other centrally planned socialist societies of Europe provide a singularly valuable laboratory to witness such experiments. 